\title{
Editorial
}

\section{The annual meeting of the Scandinavian Association for the Study of Pain (SASP) 18-20 April 2018}

Sigríður Zoëga, PhD and President of SASP ${ }^{1,2}$

1. University of Iceland, Reykjavik, Iceland

2. Landspitali - The National University Hospital of Iceland, Reykjavik, Iceland

Tel: +3548245494

Email: szoega@landspitali.is

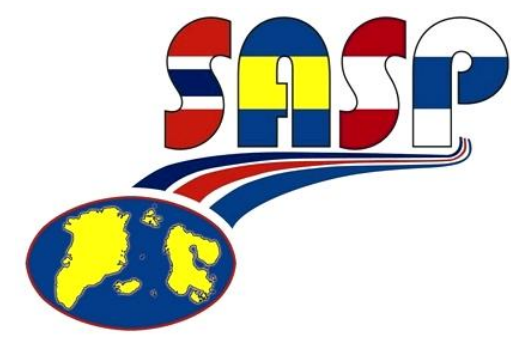

The annual meeting of SASP took place in Tampere, Finland, in collaboration with the Finnish Pain Society. The scientific program covered topics like biomarkers of pain, databanks, research collaboration, and quality of life. A one day PhD course was held in conjunction with the annual meeting for the fifth time. This is of importance, as one of the aims of SASP is to promote education and training in the area of pain research.

In this online version of the Scandinavian Journal of Pain, abstracts from the annual meeting are presented. Thirteen scientific posters were on display, covering various aspects of pain. In addition, three young researchers: Maiju Marttinen, Anders Årnes, and Rósa Hugosdóttir, who received the SASP travel awards, had the opportunity of orally presenting their work. The diversity in the topics and the quality of the work presented during the meeting reflect the status of pain research in the Nordic countries.

Best thanks to speakers, meeting organizers, delegates, and sponsors! The next annual SASP meeting will take place in Oslo, April 4th-5th 2019, titled From Cells to Societies: What do we not know about pain? Further information can be found at the meeting website www.sasp2019.com at the SASP webpage www.sasp.org and on Facebook: https://www.facebook.com/newSASP/. You can also follow both SASP@sasp_pain and the Scandinavian Journal of Pain @ScandJPain on Twitter. 